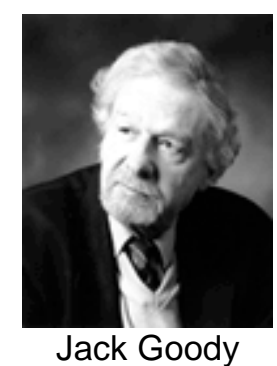

Resenha do livro The Logic of Writing and the Organization of Society de Jack Goody

\title{
Sempre atual: a lógica da escrita
}

\section{Por Patrícia Claudia da Costa Fridman}

Publicado originalmente pela Cambridge University Press, no final da década de 80, The Logic of Writing and the Organization of Society tornou-se um clássico dos estudos sobre o desenvolvimento da escrita e seus impactos, numa perspectiva antropológica.

Fruto das preocupações de Jack Goody, que desde cedo teve seu interesse voltado para a abordagem comparativa da cultura escrita, mais especificamente, para as dimensões históricas da comparação. É possível que a experiência de ter-se encontrado sem nenhum livro quando era prisioneiro de guerra, primeiro no Oriente Médio e depois na Itália, foi de crucial importância no seu interesse pela cultura escrita, ou seja, nas mudanças ocorridas nas formas de comunicação e o que elas significaram para as populações por ele estudadas.

Doutor em Antropologia, em 1919, pela Cambridge University instituição que o tornou professor honorário em 1954 - Goody estudou as sociedades do norte de Gana, nos anos 50 e 60. Deste estudo decorre $A$ lógica da escrita e a organização da sociedade. 
Nesta obra, Goody defende a tese de que a introdução da escrita nas sociedades humanas provocou grandes mudanças nas suas estruturas. Para firmar tal posição, o autor analisou o impacto da escrita, no Oriente Próximo e na África Contemporânea, nas dimensões religiosa, econômica, política e jurídica.

A abordagem é essencialmente antropológica com, interesse centrado nas questões acerca da cultura, da identidade e das religiões.

A novidade é que este autor se destaca pela recusa da visão dicotômica sobre os fenômenos estudados. Apesar de partir do paradigma antropológico de Levi-Strauss, marcado pelos pares "cru-cozido", "atrasado-avançado", "selvagem-civilizado" e daí por diante, Goody se coloca contra as duas posições extremas: nega a visão etnocêntrica, que estabelece a diferença entre letrados e iletrados, ao mesmo tempo em que denuncia a ingenuidade da crença no relativismo cultural.

A obra escapa da dicotomia etnocentrismo-relativismo pela via da "diferença cultural", ou seja, propõe que as culturas sejam consideradas por aquilo que são, sem determinação de juízo de valor.

$\mathrm{Na}$ dimensão religiosa, a grande mudança possibilitada pelo advento da escrita foi a existência das "religiões de conversão". Nas sociedades ágrafas, as práticas religiosas eram transmitidas de forma oral e, portanto, para ser adepto da religião local era necessário que o indivíduo realmente pertencesse ao grupo e vivesse imerso na cultura da qual a religião emanava, como forma natural de posicionar-se no mundo; o aprendizado acerca das questões religiosas dava-se através do contato com os mais velhos e com os costumes locais, que poderiam sofrer alterações de geração para geração. Nas sociedades letradas, as religiões passam a ter como base não mais o contato oral entre iniciados e iniciantes, mas um "livro sagrado".

Com isso, uma série de mudanças passa a diferenciar as religiões de conversão e, conseqüentemente, a marcar diferenças estruturais nas sociedades que a elas aderem. Num primeiro plano, as religiões letradas não são consideradas superiores apenas pelo fato de seus sacerdotes serem 
letrados e poderem ler bem, mas também por poderem fornecer à sua congregação a possibilidade de ela própria se tornar letrada. Aderir a uma crença depende não mais da transmissão oral dos seus ritos e preces, mas do conhecimento dos textos sagrados que, por muito tempo, foram de acesso exclusivo dos sacerdotes. Com todos os preceitos fixados na "sagrada escritura", as religiões de conversão não são mais tão "adaptáveis à realidade local" como eram as religiões das sociedades ágrafas, nas quais os exemplos com situações cotidianas (mutáveis com o correr das gerações) davam força aos ensinamentos. Passam, então, a firmarem-se num rígido sistema de crenças e ritos.

Goody analisou que as religiões letradas influenciam a estrutura normativa de um sistema social, no sentido do universalismo, de duas maneiras marcantes: primeiro, na medida em que a religião provém de alguma forma do "exterior", pelo processo de conversão e expansão, suas normas são necessariamente aplicadas a mais de um grupo ou de uma sociedade; e segundo, as formulações escritas encorajam a generalização das normas, através da tendência de apresentar uma única fórmula abstrata que se sobrepõe a normas mais contextualizadas das sociedades orais e, até certo ponto, as substitui.

$\mathrm{Na}$ dimensão econômica, a escrita contribuiu em dois aspectos gerais: na troca (comércio efetivamente) e na gestão dos assuntos econômicos do templo e do palácio. Contudo, uma vez introduzida, ela afetou outras áreas da escrita.

Segundo Goody, a questão central da contribuição da escrita para a economia tem a ver com o seu papel no desenvolvimento das sociedades, relacionado à promoção de novas tecnologias e divisão do trabalho a elas associada; ao alargamento das possibilidades do comércio e da produção; à transformação dos métodos de acumulação de capital; e à alteração da natureza das transações individuais de tipo econômico.

Uma das razões porque a escrita era tão útil no comércio estudado estaria na sua capacidade de armazenar informações ao longo do tempo, tornando assim a "memória" mais fidedigna, ou seja, a confirmação de uma 
transação já não residia na longevidade de testemunhas oculares apenas, mas na retenção de documentos, validados por meio de assinaturas ou marcas, além das próprias testemunhas.

Na dimensão política, Goody observou que a escrita era essencial para a organização de um certo tipo de Estado, o estado burocrático.

Neste tipo de estado, podemos perceber claramente que a regulamentação de regras pressupõe a escrita como elemento transformador da relação entre governantes e governados. Para citar apenas um exemplo, podemos destacar a questão do sufrágio universal. A participação democrática da massa popular está intrinsecamente relacionada ao domínio do código escrito. Para começar, o número de indivíduos registrados para fins eleitorais deve ser estabelecido por métodos de recenseamento e, muito embora a eleição possa ser organizada por meio de balcões e caixas que exibam símbolos gráficos, a inscrição dos eleitores e a contagem dos votos está nas mãos dos letrados. O simples fato de o voto passar a ser uma ação secreta, em oposição às práticas próprias das sociedades orais, nas quais as votações se davam por aclamação, confere à organização dos pleitos, pelo uso da escrita, uma qualidade verdadeiramente democrática, ao isentar os eleitores do medo e da parcialidade.

E, o mais importante, apenas os letrados têm condições de funcionar efetivamente neste sistema político, tendo em vista que todo o trabalho burocrático, que o governo e o partido produzem, exige o domínio da leitura e da escrita. Como consequiência, para ser candidato a um cargo, alto ou baixo, é preciso saber ler e escrever; caso contrário, o sujeito não tem utilidade no estado burocrático.

Finalmente, a última dimensão estudada por Goody foi a esfera jurídica. Em sua análise, o código escrito dá um novo formato à lei, relacionado com os modos de comunicação, e não limitado a uma simples questão de troca de um conjunto de práticas culturais por outra. Sendo assim, o código escrito não dá origem nem à opressão, nem à justiça. Ele apenas viabiliza um maior distanciamento entre indivíduo e linguagem, uma maior objetivação que aumenta o potencial analítico dos usuários da lei. 
A mudança provocada pela escrita incide diretamente no nível da argumentação, ajudando a transformar idéias de como a sociedade pode utilizar o passado (por meio de precedentes) e ordenar o futuro (pela legislação). Resumidamente, o processo jurídico torna-se intimamente relacionado com a idéia de verdade, por meio da prova documental, ao passo que as possibilidades de universalização e de publicidade das regras e das deliberações legais também podem ser apontadas como produtos da expansão da escrita.

Vemos, então, que a obra de Goody permanece absolutamente esclarecedora e necessária para estudantes, professores e interessados em geral sobre as questões relacionadas aos impactos do código escrito nas sociedades humanas. Considerando a situação atual, na qual uma significativa parcela da população mundial permanece à margem da lei desconhecimento de seus direitos —, da política - alheamento das possibilidades de participação na vida pública —, e da economia utilização precária dos meios de produção e de controle financeiro de suas humildes atividades produtivas -, podemos perceber a atualidade do pensamento de Goody para a compreensão não apenas das diferenças entre sociedades orais e letradas, mas também das disparidades existentes entre os grupos sociais letrados e não-letrados no interior de uma mesma sociedade, na qual a escrita organiza a lógica da sua organização.

Não podemos nos esquecer, também, dos indivíduos que, em tais sociedades, ainda permanecem religiosamente dependentes, pela falta de domínio da leitura e da escrita, gerando uma situação em que um amplo espaço se abre para a proliferação das mais diversas crenças e formas de tutela espiritual, assim como para o crescimento de um desejo, cada vez mais evidente, de aprendizado da língua escrita como meio de autonomia em questões relacionadas com o acesso aos textos sagrados.

Falando em língua escrita, encerramos com a informação de que, em nossa língua portuguesa, temos acesso à obra A lógica da escrita e a organização da sociedade, através da primorosa publicação da Editora Edições 70, de Lisboa, como parte da coleção "Perspectivas do 
Homem", na qual outros autores clássicos da antropologia também foram publicados, tais como Levi-Strauss, Evans-Pritchard, Mircea Eliade e Bronislaw Malinowski.

\section{Referências bibliográficas}

GOODY, Jack. (1992) The Logic of Writing and the Organization of Society. New York : Cambridge University Press.

GOODY, Jack. (1986) A lógica da escrita e a organização da sociedade. Lisboa : Edições 70

\section{Patrícia Claudia da Costa Fridman}

Mestranda em Educação - FEUSP.

Coordenadora do Movimento de Alfabetização de Jovens e Adultos de Guarulhos - MOVA-Guarulhos.

Av. Monteiro Lobato, 713, Macedo - Guarulhos - CEP 07111-030

Fone: (11) 6472-5423

guaruspeleo@yahoo.com.br

\section{Como citar esta resenha:}

FRIDMAN, Patrícia Claudia da Costa. The Logic of Writing and the Organization of Society de Jack Goody - Resenha. Revista ACOALFAplp: Acolhendo a Alfabetização nos Países de Língua portuguesa, São Paulo, ano 1, n. 1, 2006. Disponível em: <http://www.acoalfaplp.net>. Publicado em: setembro de 2006. 